\title{
ReSearch of ABS AND PLA Materials in THE Process OF FUSED DEPOSITION MODELING METHOD
}

\author{
Ján Milde, Róbert Hrušecký, Rudolf Zaujec, Ladislav Morovič \& Augustín Görög
}
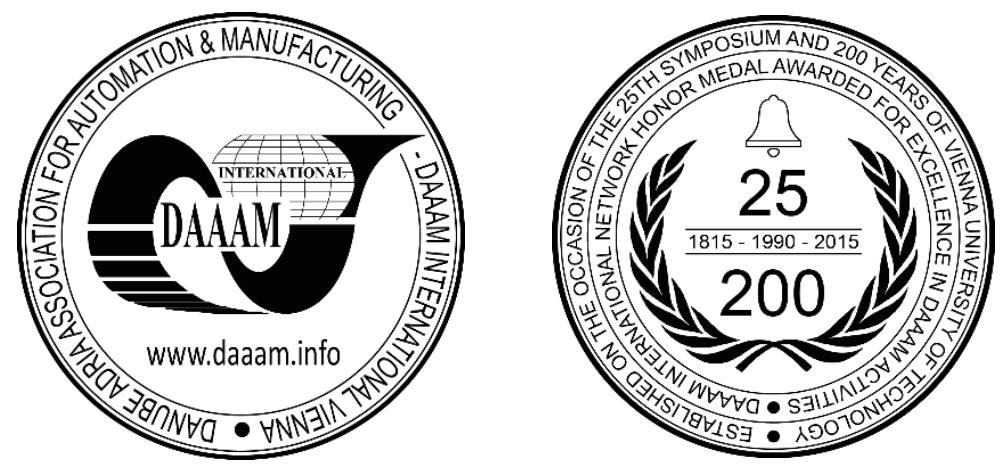

This Publication has to be referred as: Milde, J[an]; Hrusecky, R[obert]; Zaujec, R[udolf]; Morovic, L[adislav] \& Gorog, A[ugustin] (2017). Research of ABS and PLA Materials in the Process of Fused Deposition Modeling Method, Proceedings of the 28th DAAAM International Symposium, pp.0812-0820, B. Katalinic (Ed.), Published by DAAAM International, ISBN 978-3-902734-11-2, ISSN 1726-9679, Vienna, Austria

DOI: $10.2507 / 28$ th.daaam.proceedings. 114

\begin{abstract}
This article focused on comparing of the properties of the two most used materials, Acrylonitrile-Butadiene-Styrene (ABS) and Polylactic Acid (PLA), in the Rapid Prototyping (RP) process using the Fused Deposition Modeling (FDM) method. The thin-walled components were manufactured by Zortrax M200 and DeeGreen 3D printer. Print settings and printer parameters are also mentioned in the article. The printed models were 3D digitized using the GOM ATOS Triple Scan II optical 3D scanner. Main section is focused on the analysis of individual components in the GOM Inspect software. Authors used this software to measure the individual distances. The last section of the paper focuses especially on the evaluation of obtained results in the form of tables and a chart.
\end{abstract}

Keywords: Thin-wall; FDM; ABS; PLA; 3D scanning; inspection

\section{Introduction}

While traditionally plastic material ABS has been used in FDM for industrial applications, desktop printers started with ABS but gradually shifted to PLA due to its green reputation, bio-compatibility, bio-degradability, low shrinkage and good printability. PLA based materials used in FDM printers don't have the best properties (mechanical, material). Many print defect such as curvature (especially at the corners) and warpage of printed parts are commonly observed, which become more visible as the size of printed parts increase. PLA material also suffer from weak temperature resistance, which may influence in the deformation of printed objects under elevated temperatures experienced during storage and shipping or even during usage, e.g. when the objects are placed under direct sun [1,2].

In this study we established a research which compares the dimensional accuracy of the materials in consideration and performed an experiment to establish the superiority of a material in terms of accuracy over each other. The overall inaccuracy of the printed parts being built by FDM has been one of the major challenges that need to be overcome. Errors due to warpage and shrinking dominate to the inaccuracy of the part [3]. 


\section{Statement of the problem}

The purpose of this research is comparing of dimensional accuracy of thin-walled 3D printed parts PLA and ABS when compared with dimensions of the CAD models from which these parts are printed. The ABS parts were printed using the 3D printer Zortrax M200 built by Zortrax. The PLA parts were printed using the 3D printer DeeGreen built by Be3D $[4,5]$.

The goal of this research is to evaluate the limitations of the printing material, to rule out factors that do not contribute significantly to print accuracy, and to provide a practical, quantitative guide for accuracy measurement as an engineering tool. A methodology or a practical approach for calculating accuracy of a material will be developed which can be used in future to test accuracy. It will establish which material is more accurate and what is the reason behind it. Part, which was fabricated and evaluated, was a thin-walled extruder cover for a 3D printer.

\section{ABS and PLA materials}

Acrylonitrile-Butadiene-Styrene (ABS) is a terpolymer made by polymerizing styrene and acrylonitrile in the presence of polybutadiene. The proportions can vary from 15 to $35 \%$ acrylonitrile, 5 to $30 \%$ butadiene and 40 to $60 \%$ styrene. ABS is an engineering plastic that has butadiene part common distributed over the acrylonitrile-styrene matrix. It possesses excellent toughness, good dimensional and geometrical stability, easy processing ability, chemical resistance, and cheapness. Typically, ABS is a product of systematic polymerization of monomers, namely, acrylonitrile, butadiene, and styrene as shown in Fig. 1. [6]. Main properties of ABS plastic are following: density ( $\rho) 0,9 \frac{\mathrm{g}}{\mathrm{cm}^{3}}-1.53 \frac{\mathrm{g}}{\mathrm{cm}^{3}}$, glass transformation $\sim 105{ }^{\circ} \mathrm{C}$. ABS is amorphous and therefore has no true melting point, however $230{ }^{\circ} \mathrm{C}$ is the standard for printing.

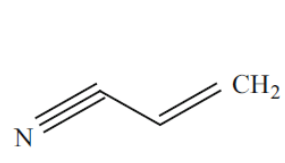

Acrylonitrile

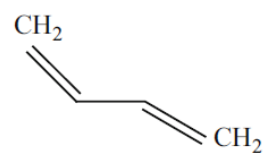

1,3 Butadiene<smiles>C=Cc1ccccc1</smiles>

Styrene<smiles>CCOC(=O)C(C)C(C)(C)C</smiles>

Fig. 2. Scheme of PLA [8]

Fig. 1. Monomer units of ABS [7]

Polylactic acid or polylactide (PLA) is a biodegradable and bioactive thermoplastic aliphatic polyester derived from renewable resources, such as corn starch, cassava roots, chips or starch, or sugarcane. PLA is very brittle, with less than $10 \%$ elongation at break, thus it is not suitable for demanding mechanical performance applications unless it is suitably modified. This material is also strongly hydrophobic and can elicit an inflammatory response from the tissues of living hosts, because of its low affinity with cells when it is used as a tissue engineering material. Another limitation of PLA material towards its wider industrial application which is limited by gas barrier properties which prevent its complete access to industrial sectors such as packaging [8]. Main properties of PLA plastic are following: density $(\rho): 1.210 \frac{\mathrm{g}}{\mathrm{cm}^{3}}-$ $1.430 \frac{\mathrm{g}}{\mathrm{cm}^{3}}$, melting point: from 150 to $160{ }^{\circ} \mathrm{C}$.

Authors Olivera S. et al. [7], focused on the properties of ABS, processes and mechanisms of plating, and studies of plating on ABS involving mainly eco-friendly methods of plating by discussing the literature published in recent years. The details of electroplating of ABS carried out in the authors' laboratory are also presented.

Authors Dunne R. et al. [9] aims on the investigates the mechanical characterization of various natural fiber composites with an ABS. The tensile strength, impact strength and air flow resistivity of samples with different densities have been measured, and have been found.

Authors Xiao L. et al. [10] focused on the properties of PLA material, biodegradability and industrial application.

Mudassir A. [3] focused on the compare the dimensional accuracy of 3D printed parts fabricated from PLA and ABS when compared with dimensions of the CAD models. The goal of this research was evaluate the limitations of the printing material, to rule out factors that do not contribute significantly to print accuracy, and to provide a practical, quantitative guide for accuracy measurement as an engineering tool. A methodology or a practical approach for calculating accuracy of a material will be developed which can be used in future to test accuracy. It will establish which material is more accurate and what is the reason behind it. 


\section{Thin-walled 3D model used for the experiment}

The model used in this experiment is thin-walled cover of extruder of 3D printer DeeGreen. This model was chosen due to its importance for manufacturing of thin-walled parts in the process of FDM. This kind of models are used in also in architecture, automotive industry, medicine, and electrotechnical industry. Buranský [12] defined thin-walled part as a part that is built by walls that are very thin. According to Trebuňa, a thin-walled profile is a profile where the wall thickness $t_{i}$ is low when considering its other dimensions. Its deformations are slight when considering the thickness of walls $b_{i}$ and that the rigidity of laying is infinitely large [13]. Aijun defined a thin-walled part as a part, where the thickness $h$ is lower than height $b$, i.e. $(1 / 80 \sim 1 / 100) b<<h<(1 / 8 \sim 1 / 5) b$, (where $h$ is the wall thickness (mm), and $b$ is the wall height $(\mathrm{mm}))[14]$.

Thickness of wall of this part is $3.00 \mathrm{~mm}$. This thin-walled model (Fig. 3) was created in Autodesk Inventor Professional 2017 software [4].

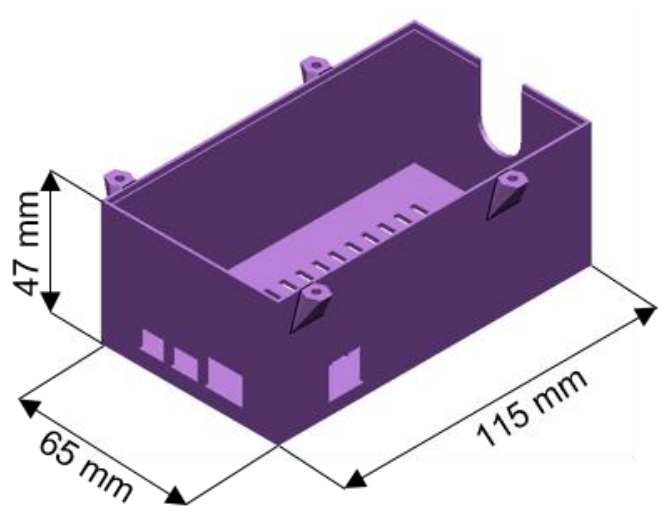

Fig. 3. Thin-walled part used in the experiment

\section{Fused Deposition Modeling method}

Fused Deposition Modeling (FDM) is a process in which a part is produced using layer-by-layer deposition of material. It is an important technology as it has potential to reduce the manufacturing lead time of the product up to $30-50 \%$ even the relative part complexity is very high. Rapid Prototyping (RP) cycle consists of creation of geometric model using a solid CAD modeler (SolidWorks, PowerSHAPE, CATIA, etc.) or 3D digitization of existing part, determination of suitable deposition orientation, slicing, generation of material deposition paths, layer thickness, internal structure and then post processing operations. Layer thickness in FDM process has significant effect on many key characteristics that determines the final quality and cost of the prototype [11].

In the FDM method, used material is in a plastic wire form, unwound from a coil. This material fiber is fed to the printing head where it is heated, fused and extruded through the nozzle in the form of fine fibers. There are several kinds of kinematic structures used in Fused Deposition Modeling.

The movements of the head and 3D printer can be divided into three most used groups:

- head is moved in axis X, Y, Z,

- head is moved in axis $\mathrm{X}, \mathrm{Y}$ and build platform is moved in $\mathrm{Z}$ axis,

- head is moved in axis $\mathrm{X}, \mathrm{Z}$ and build platform is moved in $\mathrm{Y}$ axis [11].

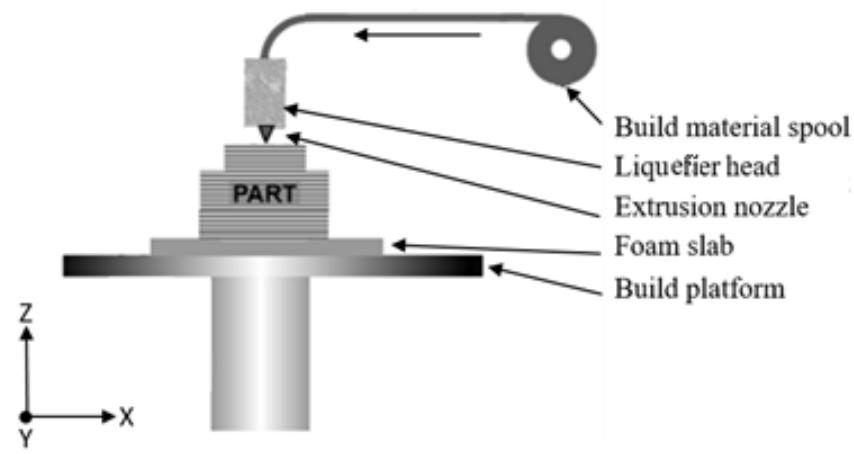

Fig. 4. Scheme of Fused Deposition Modeling [11] 


\section{Parameters settings of additive manufacturing}

In this experiment were used two FDM printer in total. The first one, Zortrax M200 3D printer was used for manufacturing of thin-walled part from ABS material. Second one, DeeGreen 3D printer was used for manufacturing of thin-walled part from PLA material.

Manufacturing parameters used for ABS and PLA parts are in the Tab. 1.

\begin{tabular}{|l|c|c|}
\hline \multicolumn{1}{|c|}{ Manufacturing parameters } & ABS part & PLA part \\
\hline Layer thickness $[\mathrm{mm}]$ & 0.10 & 0.10 \\
\hline Orientation $\left[{ }^{\circ}\right]$ & 0 & 0 \\
\hline Infill $[-, \%]$ & Medium & 50 \\
\hline Support $[\%]$ & 30 & 30 \\
\hline Quality & High & High \\
\hline
\end{tabular}

Table 1. Parameters used for manufacturing of thin-walled parts

\section{Process of measuring}

For part measuring, GOM ATOS II Triple Scan optical 3D scanner was used (Fig. 5) with measuring volume MV 170 $(170 \times 130 \times 130 \mathrm{~mm})$.

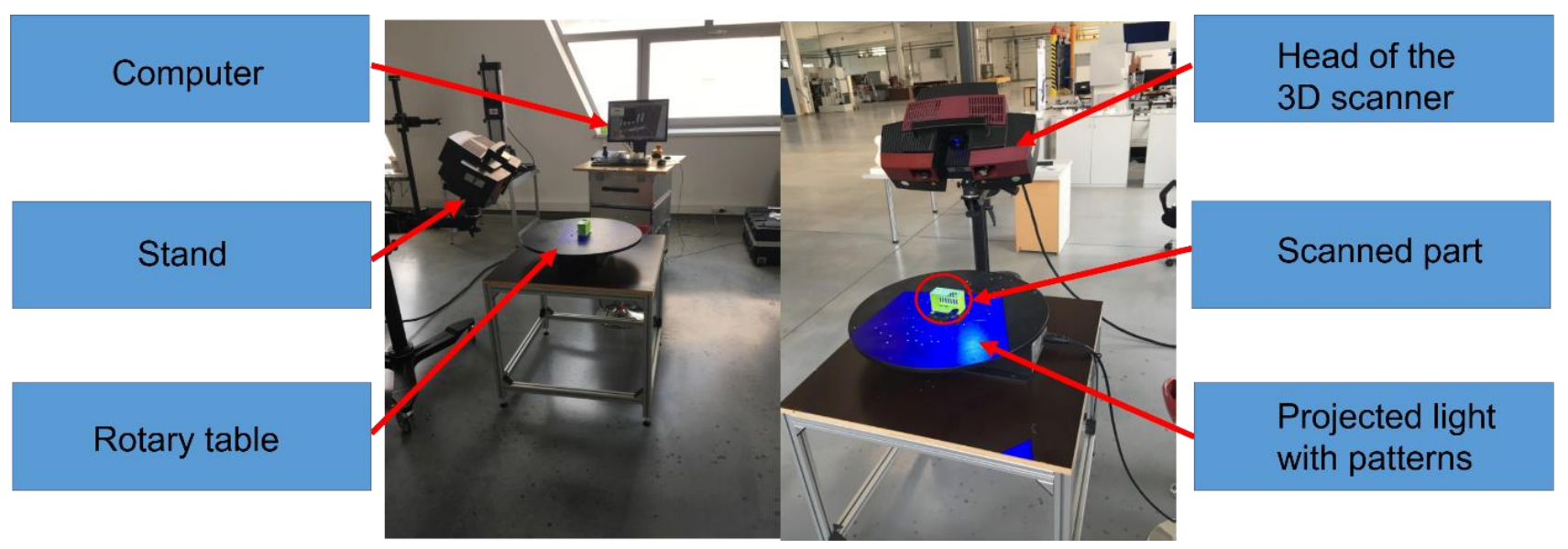

Fig. 5. GOM ATOS II Triple Scan optical 3D scanner

Before scanning, it is necessary prepare the parts for digitization (sticking the uncoded reference points to the parts $1.5 \mathrm{~mm}$ in diameter).

After 3D scanning, component can be shown in the software. Was found, that the scanner also scanned the unwanted parts. These object were removed in software. After scanning all model, it is necessary to make a comparison of parts. Parts will compare and analyze in the software GOM Inspect V8 with nominal model.

If model is imported, next step is the following: Operations - Alignment - Initial Alignment - Prealignment and both models will be set up. Then, go to the Operations - Alignment - Main Alignment - Local Best-Fit menu, mark the two models and set up. Colour deviation map was created, which serves to graphically display deviations [4].

In the second step, sections on the part were created. The sections were performed on all three axes $\mathrm{X}, \mathrm{Y}$ and $\mathrm{Z}$. Sections in the $\mathrm{X}$-axis, were performed at a distance of $67.4 \mathrm{~mm}, 110 \mathrm{~mm}$ and $139.4 \mathrm{~mm}$. Sections in the Y-axis, were performed at a distance of $23 \mathrm{~mm}$ and $73 \mathrm{~mm}$. Sections in the Z-axis were conducted of $10 \mathrm{~mm}, 25 \mathrm{~mm}$ and $40 \mathrm{~mm}$. Numerical values of deviations have been displayed for the sections thus created.

In next steps, inner and outer distances were measured in the $\mathrm{Y}$-axis and $\mathrm{X}$-axis for both thin-walled components. For a measurement of outer distances, function Outer Disc Caliper was used. For a measurement of inner distances, function Inner Disc Caliper was used. This functions can found in GOM Inspect software in the menu Contstruct Distance. Then, all distances on nominal and actual models were created. After creation of all measured distances, we connected this distances on nominal model with distances on actual model with the function Link to Actual Element. Measured distances was shown using the function Distance, where are also shown deviations. For better orientation in the software GOM Inspect, for a single distances we created tags. The tags was created with the marking of single elements in the menu Edit-New Tag Scene [4]. 


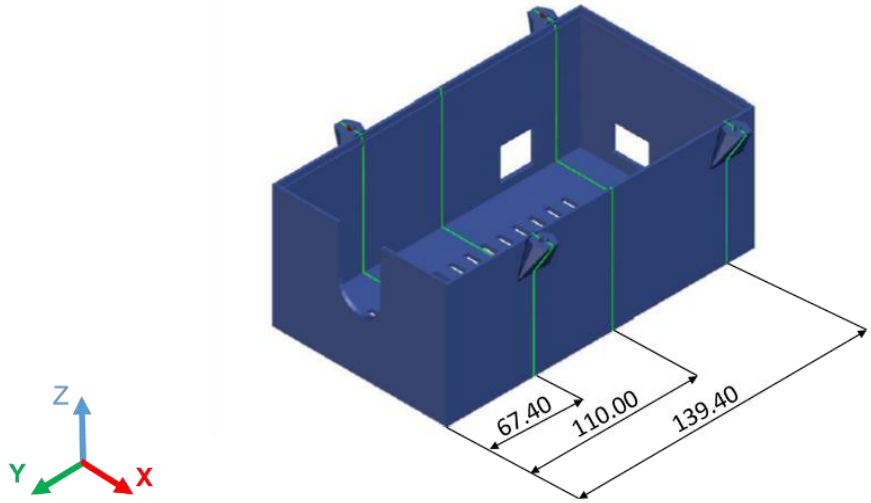

a)

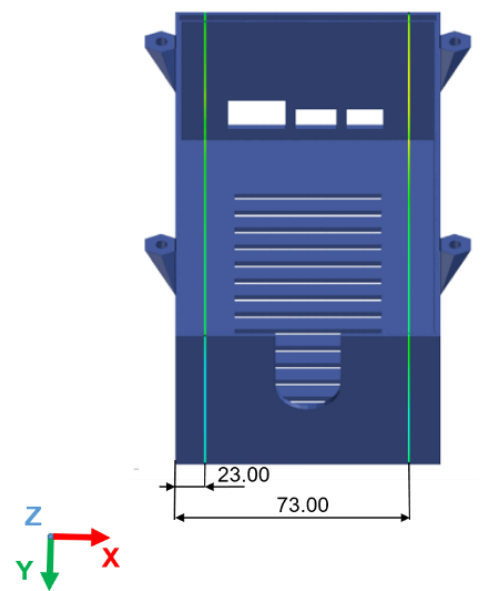

b)

Fig. 6. Sections on thin-walled component: a) section in $\mathrm{Y}$-axis, b) section in $\mathrm{X}$-axis

\section{Analysis of results}

The thin waled-part was printed six times in total. Two different printers were used for manufacturing of the parts. The model from ABS material was printed three times and model from PLA material was printed three times too. After digitizing printed models using an optical 3D scanner, the distances between two point on outer and inner surfaces was measured. The analysis of the measured values is summarized in the chart (Fig. 10 according to measured values listed in the tables $2-9$. The measuring of distances was done in the software GOM Inspect V8.

Measurements are divided into:

- measurement of Y-axis distance $\mathrm{Y}$,

- measurement of outer surfaces in $\mathrm{X}, \mathrm{Y}$ axis,

- measurement of inner surfaces in the $\mathrm{X}, \mathrm{Y}$ axis.

Measurement of the component was according to a certain principle. Measurement points were chosen at intersections of the cuts. Distance was measured on the $\mathrm{Y}$-axis so that the distance created at the distance $\mathrm{X}+67.4 \mathrm{~mm}$ and points where they cross the cut at $\mathrm{Z}+10,25,40 \mathrm{~mm}$, were created. After measuring these points, arithmetic mean was created of the entire section and entered the measured values table. This is principle, how to measure the other distances in the respective sections and their intersections.

After calculating of the arithmetic mean of distance, values were imported into one common chart (Fig. 10). Measurement of Y-axis is shown on Fig. 7

\begin{tabular}{|c|c|c|c|c|c|c|}
\hline \multicolumn{7}{|c|}{ Measurement of outer distances in Y-axis - ABS material } \\
\hline $\begin{array}{c}\text { Section X } \\
{[\mathbf{m m}]}\end{array}$ & $\begin{array}{c}\text { Nominal value } \\
{[\mathbf{m m}]}\end{array}$ & $\begin{array}{c}\text { Print 1 } \\
{[\mathbf{m m}]}\end{array}$ & $\begin{array}{c}\text { Print 2 } \\
{[\mathbf{m m}]}\end{array}$ & $\begin{array}{c}\text { Print 3 } \\
{[\mathbf{m m}]}\end{array}$ & $\begin{array}{c}\text { Arithmetic } \\
\text { means [mm] }\end{array}$ & $\begin{array}{c}\text { Deviation } \\
{[\mathbf{m m}]}\end{array}$ \\
\hline$[67.40]$ & 65.00 & 64.43 & 64.52 & 64.71 & 64.55 & -0.44 \\
\hline$[110.00]$ & 65.00 & 64.73 & 64.66 & 64.92 & 64.77 & -0.23 \\
\hline$[139.40]$ & 65.00 & 64.67 & 64.59 & 64.64 & 64.63 & -0.36 \\
\hline \multicolumn{7}{|c|}{ Arithmetic mean of ABS prints in Y-section [mm] } \\
\hline
\end{tabular}

Table 2. Measurement of outer distances in Y-axis - ABS material

\begin{tabular}{|c|c|c|c|c|c|c|}
\hline \multicolumn{7}{|c|}{ Measurement of outer distances in Y-axis - PLA material } \\
\hline $\begin{array}{c}\text { Section X } \\
{[\mathbf{m m}]}\end{array}$ & $\begin{array}{c}\text { Nominal value } \\
{[\mathbf{m m}]}\end{array}$ & $\begin{array}{c}\text { Print 1 } \\
{[\mathbf{m m}]}\end{array}$ & $\begin{array}{c}\text { Print 2 } \\
{[\mathbf{m m}]}\end{array}$ & $\begin{array}{c}\text { Print 3 } \\
{[\mathbf{m m}]}\end{array}$ & $\begin{array}{c}\text { Arithmetic } \\
\text { means [mm] }\end{array}$ & $\begin{array}{c}\text { Deviation } \\
{[\mathbf{m m}]}\end{array}$ \\
\hline$[67.40]$ & 65.00 & 64.66 & 64.68 & 64.80 & 64.71 & -0.28 \\
\hline$[110.00]$ & 65.00 & 64.83 & 64.82 & 64.85 & 64.83 & -0.16 \\
\hline$[139.40]$ & 65.00 & 64.76 & 64.61 & 64.89 & 64.75 & -0.24 \\
\hline \multicolumn{7}{|c|}{ Arithmetic mean of PLA prints in Y-section [mm] } \\
\hline
\end{tabular}

Table 3. Measurement of outer distances in Y-axis - PLA material 


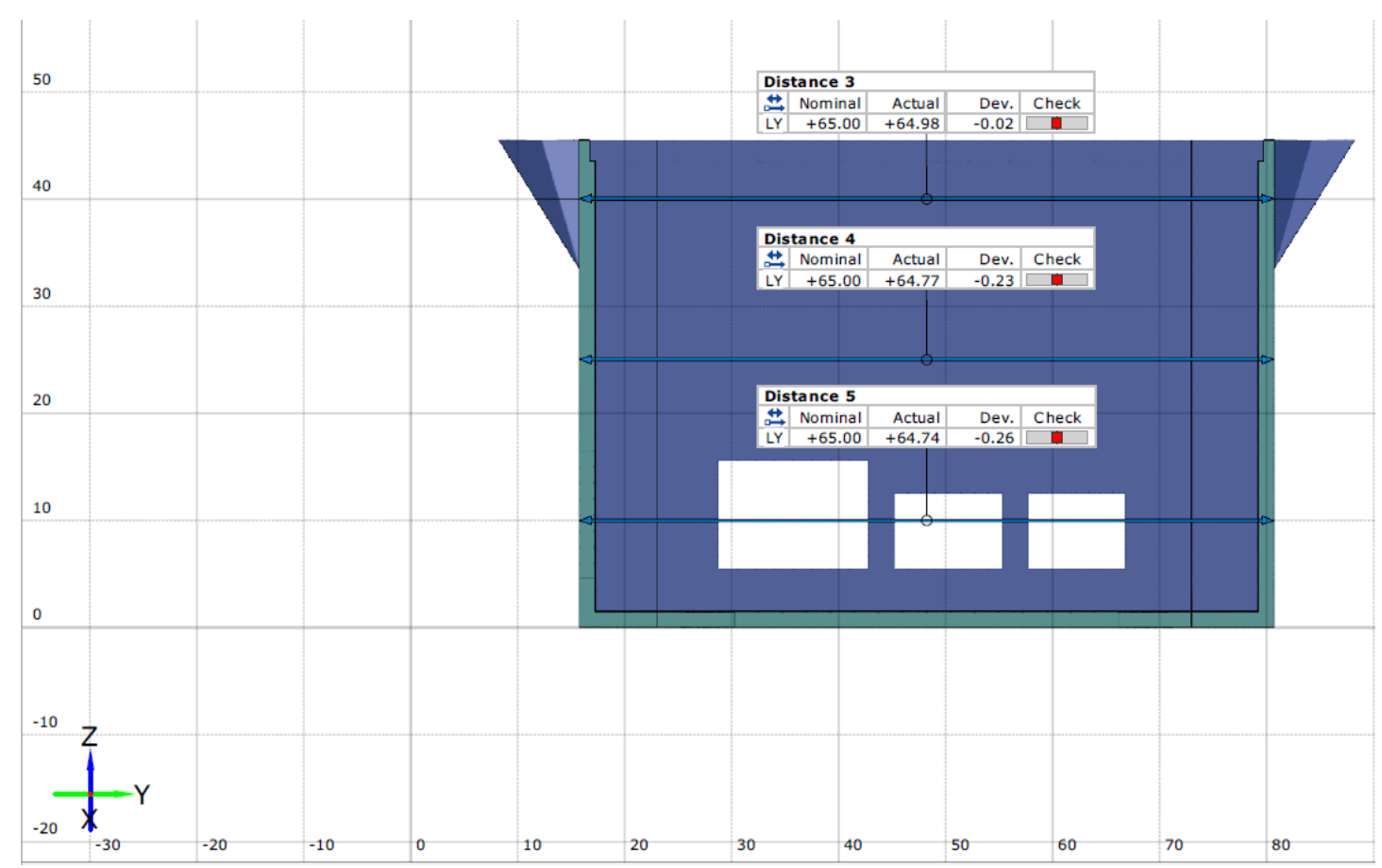

Fig. 7. Cross-section view - measurement of outer Y-axis distance Y - PLA material

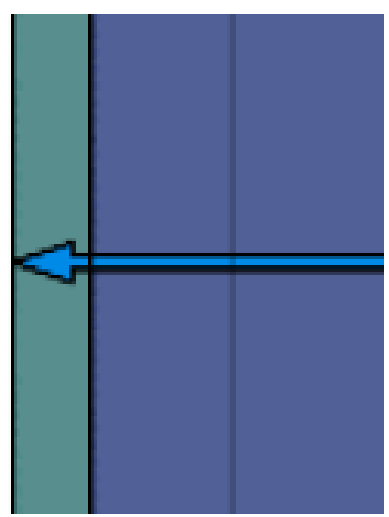

a)

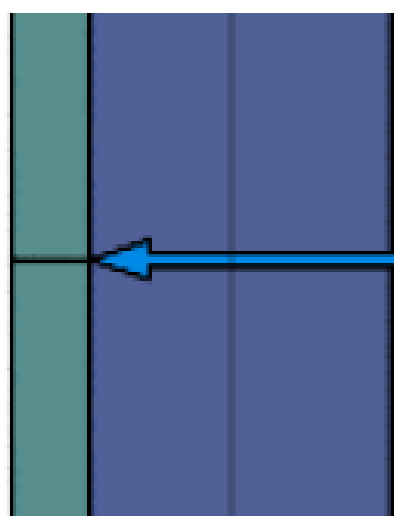

b)

Fig. 8. Difference between outer and inner distances: a) outer distance, b) inner distance

\begin{tabular}{|c|c|c|c|c|c|c|}
\hline \multicolumn{7}{|c|}{ Measurement of inner distances in X-axis - ABS material } \\
\hline $\begin{array}{c}\text { Section Y } \\
{[\mathbf{m m}]}\end{array}$ & $\begin{array}{c}\text { Nominal value } \\
{[\mathbf{m m}]}\end{array}$ & $\begin{array}{c}\text { Print 1 } \\
{[\mathbf{m m}]}\end{array}$ & $\begin{array}{c}\text { Print 2 } \\
{[\mathbf{m m}]}\end{array}$ & $\begin{array}{c}\text { Print 3 } \\
{[\mathbf{m m}]}\end{array}$ & $\begin{array}{c}\text { Arithmetic } \\
\text { means [mm] }\end{array}$ & $\begin{array}{c}\text { Deviation } \\
{[\mathbf{m m}]}\end{array}$ \\
\hline$[23.00]$ & 115.00 & 114.31 & 114.37 & 114.28 & 114.32 & -0.68 \\
\hline$[73.00]$ & 115.00 & 114.29 & 114.31 & 114.26 & 114.28 & -0.71 \\
\hline \multicolumn{7}{|c|}{ Arithmetic mean of ABS prints in X-section [mm] } \\
\hline
\end{tabular}

Table 4. Measurement of outer distances in X axis - ABS material

\begin{tabular}{|c|c|c|c|c|c|c|}
\hline \multicolumn{7}{|c|}{ Measurement of inner distances in X-axis - PLA material } \\
\hline $\begin{array}{l}\text { Section Y } \\
{[\mathrm{mm}]}\end{array}$ & $\begin{array}{c}\text { Nominal value } \\
{[\mathrm{mm}]}\end{array}$ & $\begin{array}{c}\text { Print 1 } \\
\text { [mm] }\end{array}$ & $\begin{array}{c}\text { Print } 2 \\
{[\mathrm{~mm}]}\end{array}$ & $\begin{array}{c}\text { Print } 3 \\
{[\mathrm{~mm}]}\end{array}$ & $\begin{array}{l}\text { Arithmetic } \\
\text { means [mm] }\end{array}$ & $\begin{array}{c}\text { Deviation } \\
\text { [mm] }\end{array}$ \\
\hline [23.00] & 115.00 & 114.78 & 114.63 & 114.43 & 114.61 & -0.38 \\
\hline [73.00] & 115.00 & 114.78 & 114.67 & 114.39 & 114.61 & -0.38 \\
\hline \multicolumn{6}{|c|}{ Arithmetic mean of PLA prints in X-section [mm] } & -0.38 \\
\hline
\end{tabular}

Table 5. Measurement of outer distances in X axis - ABS material 


\begin{tabular}{|c|c|c|c|c|c|c|}
\hline \multicolumn{7}{|c|}{ Measurement of inner distances in Y-axis - ABS material } \\
\hline $\begin{array}{c}\text { Section X } \\
{[\mathbf{m m}]}\end{array}$ & $\begin{array}{c}\text { Nominal value } \\
{[\mathbf{m m}]}\end{array}$ & $\begin{array}{c}\text { Print 1 } \\
{[\mathbf{m m}]}\end{array}$ & $\begin{array}{c}\text { Print 2 } \\
{[\mathbf{m m}]}\end{array}$ & $\begin{array}{c}\text { Print 3 } \\
{[\mathbf{m m}]}\end{array}$ & $\begin{array}{c}\text { Arithmetic } \\
\text { means [mm] }\end{array}$ & $\begin{array}{c}\text { Deviation } \\
{[\mathbf{m m}]}\end{array}$ \\
\hline$[67.40]$ & 62.00 & 61.76 & 61.92 & 61.77 & 61.81 & -0.18 \\
\hline$[110.00]$ & 62.00 & 61.95 & 61.88 & 61.82 & 61.88 & -0.11 \\
\hline$[139.40]$ & 62.00 & 61.92 & 61.93 & 61.93 & 61.84 & -0.15 \\
\hline \multicolumn{7}{|c|}{ Arithmetic mean of ABS prints in Y-section [mm] } \\
\hline
\end{tabular}

Table 6. Measurement of inner distances in Y axis - ABS material

\begin{tabular}{|c|c|c|c|c|c|c|}
\hline \multicolumn{7}{|c|}{ Measurement of inner distances in Y-axis - PLA material } \\
\hline $\begin{array}{c}\text { Section X } \\
{[\mathbf{m m}]}\end{array}$ & $\begin{array}{c}\text { Nominal value } \\
{[\mathbf{m m}]}\end{array}$ & $\begin{array}{c}\text { Print 1 } \\
{[\mathbf{m m}]}\end{array}$ & $\begin{array}{c}\text { Print 2 } \\
{[\mathbf{m m}]}\end{array}$ & $\begin{array}{c}\text { Print 3 } \\
{[\mathbf{m m}]}\end{array}$ & $\begin{array}{c}\text { Arithmetic } \\
\text { means [mm] }\end{array}$ & $\begin{array}{c}\text { Deviation } \\
{[\mathbf{m m}]}\end{array}$ \\
\hline$[67.40]$ & 62.00 & 61.77 & 61.65 & 61.68 & 61.70 & -0.30 \\
\hline$[110.00]$ & 62.00 & 61.72 & 61.77 & 61.75 & 61.74 & -0.25 \\
\hline$[139.40]$ & 62.00 & 61.76 & 61.74 & 61.71 & 61.73 & -0.26 \\
\hline \multicolumn{7}{|c|}{ Arithmetic mean of ABS prints in Y-section [mm] } \\
\hline
\end{tabular}

Table 7. Measurement of inner distances in Y axis - PLA material

\begin{tabular}{|c|c|c|c|c|c|c|}
\hline \multicolumn{7}{|c|}{ Measurement of inner distances in X-axis - ABS material } \\
\hline $\begin{array}{c}\text { Section Y } \\
{[\mathbf{m m}]}\end{array}$ & $\begin{array}{c}\text { Nominal value } \\
{[\mathbf{m m}]}\end{array}$ & $\begin{array}{c}\text { Print 1 } \\
{[\mathbf{m m}]}\end{array}$ & $\begin{array}{c}\text { Print 2 } \\
{[\mathbf{m m}]}\end{array}$ & $\begin{array}{c}\text { Print 3 } \\
{[\mathbf{m m}]}\end{array}$ & $\begin{array}{c}\text { Arithmetic } \\
\text { means [mm] }\end{array}$ & $\begin{array}{c}\text { Deviation } \\
{[\mathbf{m m}]}\end{array}$ \\
\hline$[23.00]$ & 112.00 & 111.53 & 111.61 & 111.52 & 111.55 & -0.44 \\
\hline$[73.00]$ & 112.00 & 111.51 & 111.64 & 111.48 & 111.54 & -0.45 \\
\hline \multicolumn{7}{|c|}{ Arithmetic mean of ABS prints in X-section [mm] } \\
\hline
\end{tabular}

Table 8. Measurement of inner distances in X axis - ABS material

\begin{tabular}{|c|c|c|c|c|c|c|}
\hline \multicolumn{7}{|c|}{ Measurement of inner distances in X-axis - PLA material } \\
\hline $\begin{array}{c}\text { Section Y } \\
{[\mathbf{m m}]}\end{array}$ & $\begin{array}{c}\text { Nominal value } \\
{[\mathbf{m m}]}\end{array}$ & $\begin{array}{c}\text { Print 1 } \\
{[\mathbf{m m}]}\end{array}$ & $\begin{array}{c}\text { Print 2 } \\
{[\mathbf{m m}]}\end{array}$ & $\begin{array}{c}\text { Print 3 } \\
{[\mathbf{m m}]}\end{array}$ & $\begin{array}{c}\text { Arithmetic } \\
\text { means [mm] }\end{array}$ & $\begin{array}{c}\text { Deviation } \\
{[\mathbf{m m}]}\end{array}$ \\
\hline$[23.00]$ & 112.00 & 111.55 & 111.73 & 111.68 & 111.65 & -0.34 \\
\hline$[73.00]$ & 112.00 & 111.51 & 111.77 & 111.70 & 111.66 & -0.34 \\
\hline \multicolumn{7}{|c|}{ Arithmetic mean of ABS prints in X-section [mm] } \\
\hline
\end{tabular}

Table 9. Measurement of inner distances in X axis - PLA material

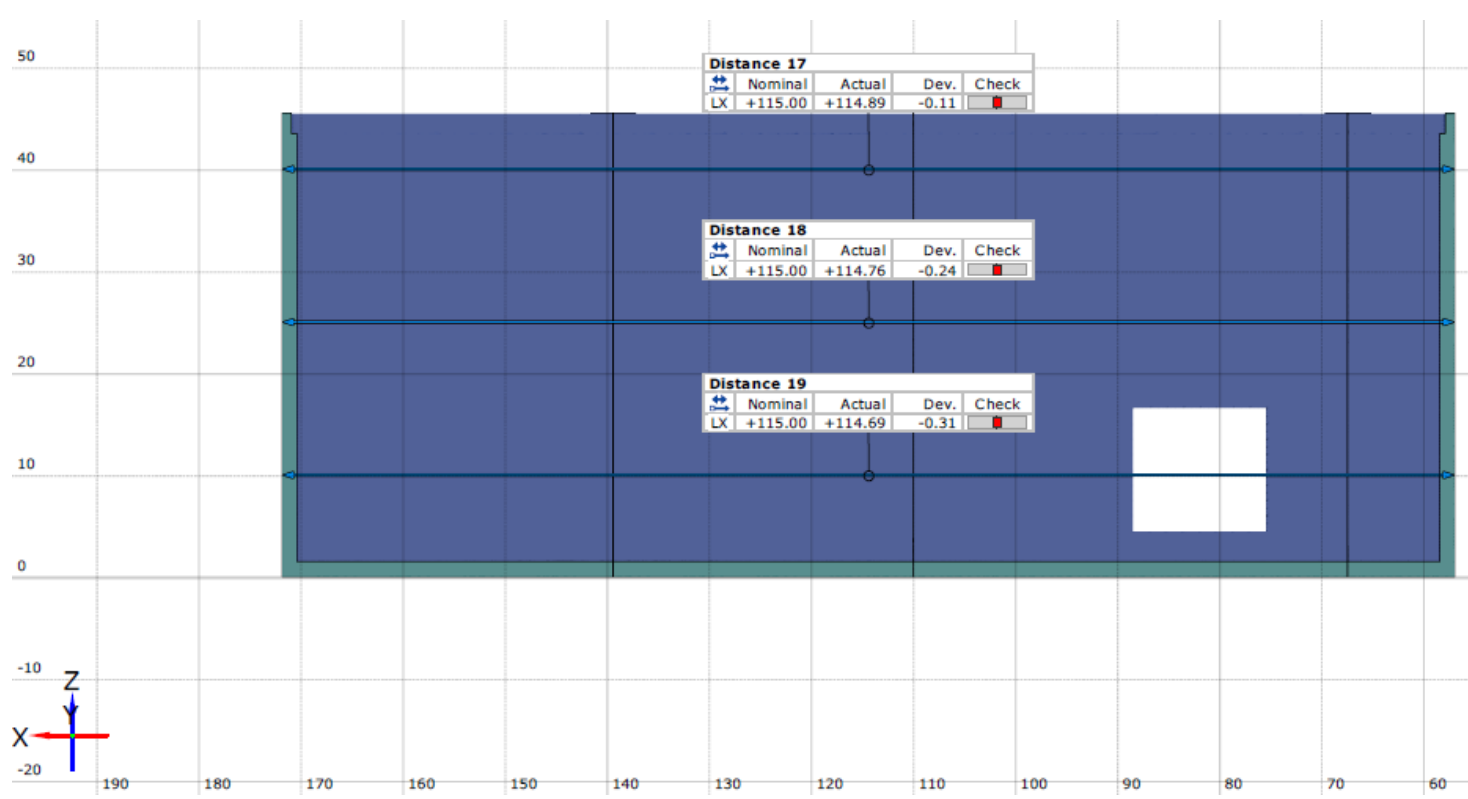

Fig. 9. Measurement of distances in $\mathrm{X}$ axis 


\section{Comparison of ABS and PLA material}

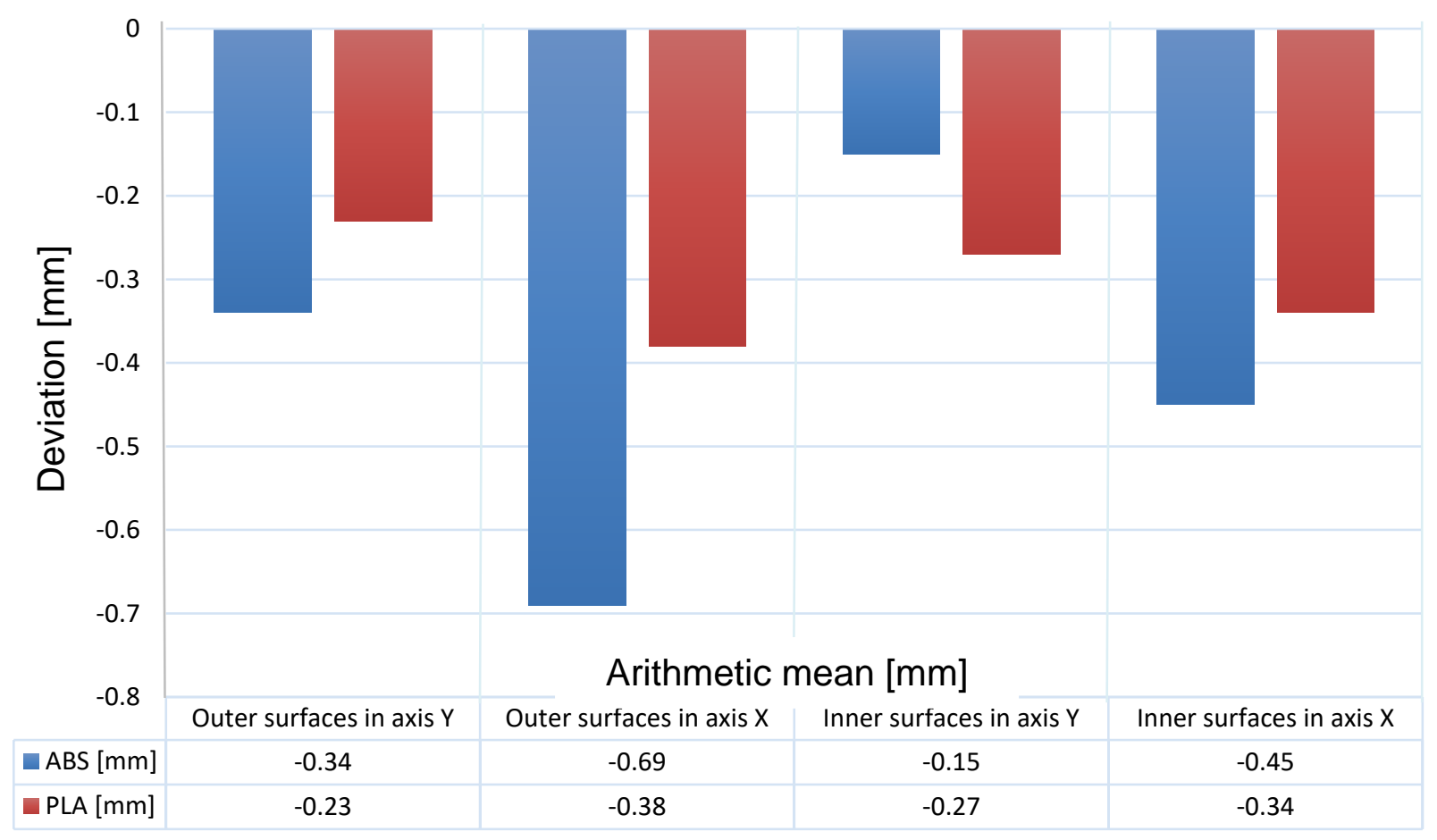

$\square \mathrm{ABS}[\mathrm{mm}] \quad$-PLA $[\mathrm{mm}]$

Fig. 10. Comparison of deviation of ABS and PLA thin-walled components

\section{Conclusion}

The shrinkage of plastics designates the volume contraction of polymers during the cooling step of the processing of polymers. This contraction is partly due to the difference of density of polymers from the melt state and the cooled, rigid state. In the process of molding is known, that ABS plastic is susceptible to shrinkage. Problem was, to know how is the dimensional differences between two most used materials in the additive manufacturing method known as Fused Deposition Modeling.

Component was designed in the Autodesk Inventor Professional 2017 CAD software. Thin-walled parts were manufactured by additive manufacturing with the technology, common known as Fused Deposition Modeling. Zortrax M200 3D printer was used for ABS components and for PLA part was used Be3D DeeGreen 3D printer. Before fabrication, converting the CAD model on to .stl format was necessary. After import the .stl file to the printer, the print process was set. Z-Suite and DeeControl software offer following properties: layer thickness $0.09 \mathrm{~mm}$, high quality, medium infill (50\%), 9 full top layers, 4 full bottom layers and automatic fan speed. Orientation of model was set as $0^{\circ}$. Created CAD model was printed on two different printers, so we had to repeat the same procedure on the DeeGreen printer. Six parts was made in total. Three for ABS and three for PLA material. At the third point, it was necessary to digitize the printed components. Digitization was realized at the Centre of Excellence of the 5-Axis Machining of STU MTF in Trnava. Measure volume was used MV 170. Before scanning, printed models had to be marked for scanning by attaching $1.5 \mathrm{~mm}$ reference points. After scans of the first series of scanning, component was turned to scan all the faces, and we combined these series of scans into one. We have been able to export the scanned model to the .stl format.

The data was divided according to the measurement method. After evaluating the experiment, was found that the actual impact on the resulting quality and speed of production was due to the used printer itself. The time of manufacturing of ABS components was 3 hours and 54 minutes longer than the PLA material. In the overall assessment, for ABS components was needed 8 hours 42 minutes more time to manufacture. According to Fig. 10 the biggest difference between components manufactured for ABS and PLA materials was measurement on outer surfaces in X-axis. The value was more than $0.3 \mathrm{~mm}$ higher for components from ABS material. Because is known, that ABS material is more prone to retraction than PLA. The measurement of X-axis of outer surfaces was the highest distance and the reason for the largest deviation was retraction. In just one case, the value of the ABS material was less than the PLA material. It was in case measurement of inner surfaces in Y- axis. Subsequent digitization and component inspections were found: the PLA material is less susceptible to shrinkage at the $\mathrm{X}$ and $\mathrm{Y}$-axis outer surfaces. The ABS material exhibited smaller mean 
deviations on the Y-axis inner surfaces. The arithmetic mean deviation of the Y-axis contour of the outer surfaces is less for the PLA material $(0.23 \mathrm{~mm})$ compared to the ABS material $(0.34 \mathrm{~mm})$. Comparison of this measured distances are shown on Fig. 10. The biggest deviation was on ABS part on outer surfaces in X - axis with the value $0.6967 \mathrm{~mm}$. That the PLA material was less susceptible to shrinking the plastic on the $\mathrm{X}$ and $\mathrm{Y}$-axis outer surfaces measured. The ABS material was less prone to the $\mathrm{Y}$-axis inner surfaces.

Suggestions for future advanced research in this area are following: print the same model from other available plastic materials as High Impact Polystyrene (HIPS), Polycarbonate combined with Acrylonitrile-Butadiene-Styrene (PCABS) and Polyethylene terephthalate glycol (PET-G). Manufacturing of circular components by the FDM technology and measuring of them in the second step will be also good suggestion for future research.

\section{Acknowledgments}

The authors would like to thank for financial contribution from the STU Grant scheme for Support of Young Researchers project no. 1375 with acronym "SKOPF" and the project VEGA 1/0477/14. Research of influence of selected characteristics of machining process on achieved quality of machined surface and problem free assembly using high Technologies.

\section{References}

[1] Kochesfahani S. H. (2016). Plastics Engineering, Imerys Filtration and Performance Additives, ISSN 123-01234567, ANTEC 2016 Indianapolis, USA

[2] Kochesfahani S. H., Abler, C., Crepin-Leblond, J., Jouffret, F. (2010). Enhancing Biopolymers with High Performance Talc Products, Available from: http://www.4spe.org/Resources/resource.aspx?ItemNumber=11876

[3] Mudassir A. (2016) Measuring Accuracy of Two 3D Printing Materials, Department of Engineering Technologies, Bowling Green State University, Bowling Green, Ohio, USA

[4] Jančuš L. (2017). Research of ABS a PLA materials in the process of Fused Deposition Modeling, Department of (Bachelor's thesis). Slovak University of Technology in Bratislava, Faculty of Materials Science and Technology in Trnava, Institute of Production Technologies. Supervisor: Ing. Ján Milde

[5] Vittek, M. (2016). Influence of CAD orientation in the process of Rapid Prototyping on geometrical and dimensional accuracy of components (Bachelor's thesis). Slovak University of Technology in Bratislava, Faculty of Materials Science and Technology in Trnava, Institute of Production Technologies. Supervisor: doc. Ladislav Morovič, PhD.

[6] Olivera S., Muralidhara B. H., Venkatesh K., Gopalakrishna K., Vivek CH. S. (2016). Plating on acrylonitrilebutadiene-styrene (ABS) plastic: a review“, Journal of Material Science, Vol. 51, pp. 3657-3674, ISSN 1573-4803, https://doi.org/10.1007/s1085

[7] Plastic Properties of Acrylonitrile Butadiene Styrene (2010). Dynalab. Internet archive wayback machine. http://www.dynalabcorp.com/technical_info_abs.asp

[8] Cuiffo, M.A.; Snyder, J., Elliott, A.M.; Romero, N.; Kannan, S.; Halada, G.P. (2017). Impact of the Fused Deposition (FDM) Printing Process on Polylactic Acid (PLA) Chemistry and Structure. Appl. Sci. 2017, 7, 579.

[9] Dunne R., Desai N., and Sadiku R. (2017). Material characterization of blended sisal-kenaf composites with an ABS matrix“, Applied Acoustics, Vol. 125, pp. 184-193, 003-682X, https://doi.org/10.1016/j.apacoust.2017.03.0

[10] Xiao L., Wang B., Yang G., Gauthier M. (2012). Poly (Lactic Acid)-Based Biomaterials: Synthesis, Modification and Applications, 978-953-307-471-9, INTECH, Shanghai, China.

[11] Milde J., Morovič L. (2016). The Influence of Internal Structures in Fused Deposition Modeling Method on Dimensional Accuracy of Components. Slovak University of Technology, Faculty of Materials Science and Technology in Trnava, Institute of Production Technologies. Research Papers, Vol. 24, pp. 73-80. ISSN 1336-1589

[12] Buranský I. (2011). Thin-walled parts machining. Scientific Monographs. Hochschule Anhalt. Kolten, Germany. ISBN 978-3-86011-043-0.

[13] Trebuňa, F., Šimčák, F. (1999). Tenkostenné nosné prvky a konštrukcie. (Thin wall bearing elements and constructions). Košice: Vienala. ISBN 80-7099-444-4

[14] Aijun, T., Zhanqiang L. (2008). Deformation of thin-walled plate due to static end milling force. In Journal of Materials Processing Technology. Volume 206. http://www.sciencedirect.com 